\title{
Impacts of a Holistic Place-Based Community Internship on Participant Interest in Science and Conservation Pathways
}

\author{
Judith D. Lemus ${ }^{1}$
}

${ }^{1}$ Hawai'i Institute of Marine Biology, University of Hawai'i at Manoa

Keywords: Place-based education, science research experience, internship

Publication Date: January 19, 2018

DOI: https://doi.org/10.15695/jstem/v1i1.3

\begin{abstract}
Educational approaches that provide meaningful, relevant opportunities for place-based learning have been shown to be effective models for engaging indigenous students in science. The Laulima A'Ike Pono (LAIP) collaboration was developed to create a place-based inclusive learning environment for engaging local community members, especially Native Hawaiians and Pacific Islanders, in scientific research at a historically significant ancient Hawaiian fishpond. The LAIP internship focused on problem-solving activities that were culturally relevant to provide a holistic STEM research experience. The 3-year program was successful in engaging a high proportion of native Hawaiian and other underrepresented minority participants. Interns reported high levels of increased interest, understanding, and competency in several areas of environmental and field science. The program also influenced interest and participation in natural science, environmental studies, resource management, and community organizations for a high percentage of participants. However, no changes were observed regarding interest or plans for STEM-related coursework or majors as a result of participation. This article dis-cusses place-based science internships such as LAIP as a potential model for increasing relevancy and inclusiveness in research experiences and enhancing access to future STEM opportunities.
\end{abstract}

\section{INTRODUCTION}

Underrepresentation of minorities in STEM educational pathways and careers has been an ongoing problem for decades (NASEM, 2016; Allen-Ramdial and Campbell, 2014; NRC, 2011). Recruitment and retention in geosciences and ocean sciences seem to be particularly intractable and numerous scholarly works have been produced that attempt to shed light on and address these issues (Cook et al., 2016; Gilligan and Ebanks, 2016; (Johnson and Okoro, 2016; Gilligan et al., 2007). Although some gains have been made, parity is a long way off and geo/ocean sciences continue to lag behind many other disciplines in terms of diversity and inclusion. The disparity in representation is even more pronounced for indigenous minorities in the U.S. such as Native Hawaiians and Pacific Islanders (NHPI). According to 2016 national census data for the state of Hawai' $i$, NHPI represent $26 \%$ of the population in Hawai ' $i$, but only $16 \%$ earn Bachelor's degrees or higher, compared to $32 \%$ of the total population in Hawai'i (American Community Survey, 2016). Data from University of Hawai'i indicate 13\% of Bachelor's and $7 \%$ of graduate degrees in STEM were awarded to students of Hawaiian ancestry in the 2016-17 academic year (UH Institutional Research and Analysis Office).

A body of previous work demonstrates that lack of repre- sentation in science careers is not due to lack of aspiration by underrepresented students (Chang et al., 2014; NRC, 2011; Anderson and Kim, 2006). What then is the crux of the problem? The issue is no doubt multidimensional and complex, but one key factor may lie in the cultural disconnect between science and other ways of knowing. Western science idealizes the concept of universal theories, which can diminish the role of place, and indeed, Western scientists are conventionally trained to minimize the influence of idiosyncratic phenomena and place attachment in their approach. This philosophical underpinning of Western science can set up a conceptual and cultural dichotomy for indigenous students (Bang et al., 2007; Gibson and Puniwai, 2006; Snively and Corsiglia, 2000). Like other indigenous peoples, a sense of place holds strong importance in the identity of Hawaiians (Kana'iaupuni and Malone, 2006; Riggs et al., 2007) and understanding contextualized local knowledge is a highly valued skill (Kimmerer, 2002). Educational approaches that provide meaningful, relevant opportunities for placebased learning have been shown to be effective models for engaging indigenous students in science (Kuwahara, 2013; Sutherland and Swayze, 2012; Riggs, 2005; Semken, 2005). Likewise, programs that emphasize problem-solving activ- 
ities and community relevance are more likely to achieve success in retaining minority students in the science pipeline (Johnson and Okoro, 2016).

The Laulima A 'Ike Pono collaboration between the Hawai'i Institute of Marine Biology (HIMB) at the University of Hawai' $\mathrm{i}$ and Paepae o He'eia, a Native Hawaiian community organization, was developed to create a place-based inclusive learning environment for engaging local community members, especially Native Hawaiians and Pacific Islanders, in scientific research with university researchers at a historically significant ancient Hawaiian fishpond. Funded by the NSF Opportunities for Enhancement in the Geo-sciences initiative, the project sought to offer culturally relevant holistic geoscience and environmental research experiences for learners who have rich ancestral, cultural, emotional, or spiritual connections to their local environment (i.e., strong place identity), and for those searching to develop such an identity. In doing so, an explicit effort was made to draw synergistic connections between Hawaiian knowledge or Hawaiian science, and Western science. An important underlying goal was to "resist placing Western modern science and Native science in an oppositional dichotomy" and avoid "inappropriately simplifying both ideas of Western modern science and Native science" (Bang and Medin, 2010).

Previously established research collaborations between the University of Hawai' $\mathrm{i}$ and Paepae o He'eia were focused on addressing issues related restoring the 800 year-old

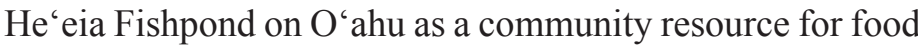
and cultural sustainability. LAIP built on those relationships to engage learners in problem-solving activities relevant to their communities (Johnson and Okoro, 2016). Rather than target only college students, a conscious decision was made to foster a broader sense of inclusiveness, community, and responsibility by offering intern-ships to all types of adult community members, regardless of age, vocational background, or educational aspirations. One intent related to this was to offer people who may be underemployed in Hawai' $i$ an opportunity to explore geosciences as a potential second or re-career pathway. Another desire was to build greater public participation in community-driven initiatives such as those led by Paepae o He'eia. This article describes the LAIP internship program as a case study for leveraging place-based learning to increase inclusiveness by creating more relevancy in STEM research experiences, especially for indigenous and other learners with strong place identity.

\section{METHODS}

The Laulima A 'Ike Pono internship was open to all community members over 17 years of age, with preference given to residents of the moku or regional district in which the fishpond is located. The program was advertised through educational institutions (university, community colleges, and high schools), community and professional organizations, and state and local agencies. Project partners at HIMB and Paepae o He'eia also worked together and with other organizations to specifically ensure outreach to Native Hawaiian and Pacific Islander communities. While potential interns were

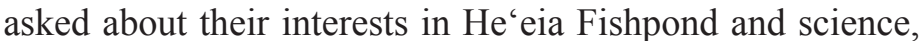
they were not asked about their race, ethnicity, or gender during the application process.

Internship Structure. Laulima A 'Ike Pono ran for three consecutive years at He'eia Fishpond in the Ko'olaupoko moku (district) of $\mathrm{O}^{\prime} \mathrm{ahu}$, Hawai'i. Cohorts of up to eight interns worked with HIMB graduate students conducting research in the fishpond for a 6-month period, with a new cohort rotating into the program each January and July (six cohorts total). Over the course of the program, 46 community members participated in the research internship. Cohorts worked at the fishpond for four hours on a weekday afternoon and eight hours every other Saturday, for a total of 32 hours per month. Research was introduced to each cohort through discussions and lessons during the first two weeks, followed by practice sessions, and finally the actual science investigations and data collection. Once the research was underway, a typical science work day would include a brief overview of the day's objective, dividing up into teams, and collecting the data. For safety and quality assurance, interns always worked in teams of at least two people.

The scientific research conducted during the project focused on three main areas: the biogeochemistry of fishpond water column and sediments, the distribution of primary producers, and the effect of invasive mangroves on fishpond trophic relationships. LAIP interns were primarily involved in data collection for each project, but occasionally were also engaged in data analysis with guidance from the graduate student research mentors. This research resulted in the production of several seasonal distribution maps beneficial to fishpond management: dissolved oxygen, salinity, $\mathrm{pH}$, chlorophyll a, suspended solids, phytoplankton, microphytobenthos, and invasive macroalgae. It also produced useful information on infaunal community change over time following invasive mangrove removal from the fishpond that helped validate the long-term benefits of the restoration efforts (Siple and Donahue, 2013).

In addition to scientific training, interns also received cultural training at the fishpond during one of the Saturday work days each month. This work was led by one of two cultural advisors and entailed a variety of approaches that included discussions of Hawaiian history and mythology, lessons in chanting, observation, hands-on practice, and service work. The goal for this portion of the training was to provide a holistic experience for interns in a way that drew connections between traditional Hawaiian and scientific ways of knowing to highlight the relevance of both epistemologies. 
For example, the Hawaiian moon calendar and chant was introduced to interns to ex-plain the influence of moon phases and tides on cultural practices in the pond, which are linked to very specific biological and ecological cycles important for food production and harvesting. This discussion of tides was also explicitly connected to specific research activities the interns were conducting, such as zoo-plankton and fish distribution, water quality, and invertebrate reproduction.

Because research work days were sometimes quite long (4 - 8 hours), food breaks and social interaction were naturally built into the internship experience. Mentors and interns alike were encouraged to bring food or other cultural items they wanted to share. Sharing of food and stories became an integral part of the program, with participants proudly bringing homemade food items, flower leis, and sometimes even musical instruments for sharing their talents, interests, and cultural identities. Frequent discussion sessions became another venue for this kind of social interaction, and an opportunity for interns to ask questions about a variety of topics, including school, career choices, the environment, and even politics.

At the end of each session, interns were grouped into pairs to work on a hand-made poster presentation about one aspect of the research they conducted. The design and development of the posters were left entirely to the interns' discretion and creativity (Figure 1). These were presented to an audience of their peers, family, friends, as well as the fishpond care-takers and scientists during a culminating social event at the fishpond. In many cases, interns also chose to present a demonstration of the actual methods or procedures they used during their research. Guests of the interns were offered guided boat and walking tours of the fishpond, which were followed by a catered potluck meal and socializing. The presentations and social served an additional important role of keeping fishpond staff and managers up to date on the results and implications of LAIP-supported research projects. While the science team worked closely with $\mathrm{He}^{\text {'eia }}$ Fishpond managers during the implementation of this program, it was still important that research results were regularly shared to ensure that all partners were well-informed and had access to emerging data for decision making.

Community interns were provided a stipend of $\$ 2000$ for the 6-month program as a small compensation for their contribution to the ongoing research. Cohorts were also informally introduced to a variety of educational and carrier pathways in STEM via group discussions with each of the science research mentors and project lead faculty. Additional ad hoc mentor-ship in college application or essay preparation, recommendations to other internships, and career advice was provided according to interns' individual interests and requests.

Evaluation and Assessment. Evaluation followed a onegroup, pre-test-post-test design similar to Knapp et al. (2010). Data collection included survey assessments to understand participants' overall experience in the internship, as well as determine the extent to which program objectives had been achieved. An overarching question underlying the goal of the LAIP program was whether a place-based, culturally-connected, and relevant science research experience would increase interest in pursuing further education or career opportunities in STEM-related fields for underrepresented local participants, especially NHPI minorities. Three LAIP program objectives are relevant to the study reported here:

1. Provide Native Hawaiians culturally relevant opportunities to explore geosciences through community internships and college mentoring.

2. Integrate scientific methodologies and technology with traditional knowledge and practices to create a holistic edu-

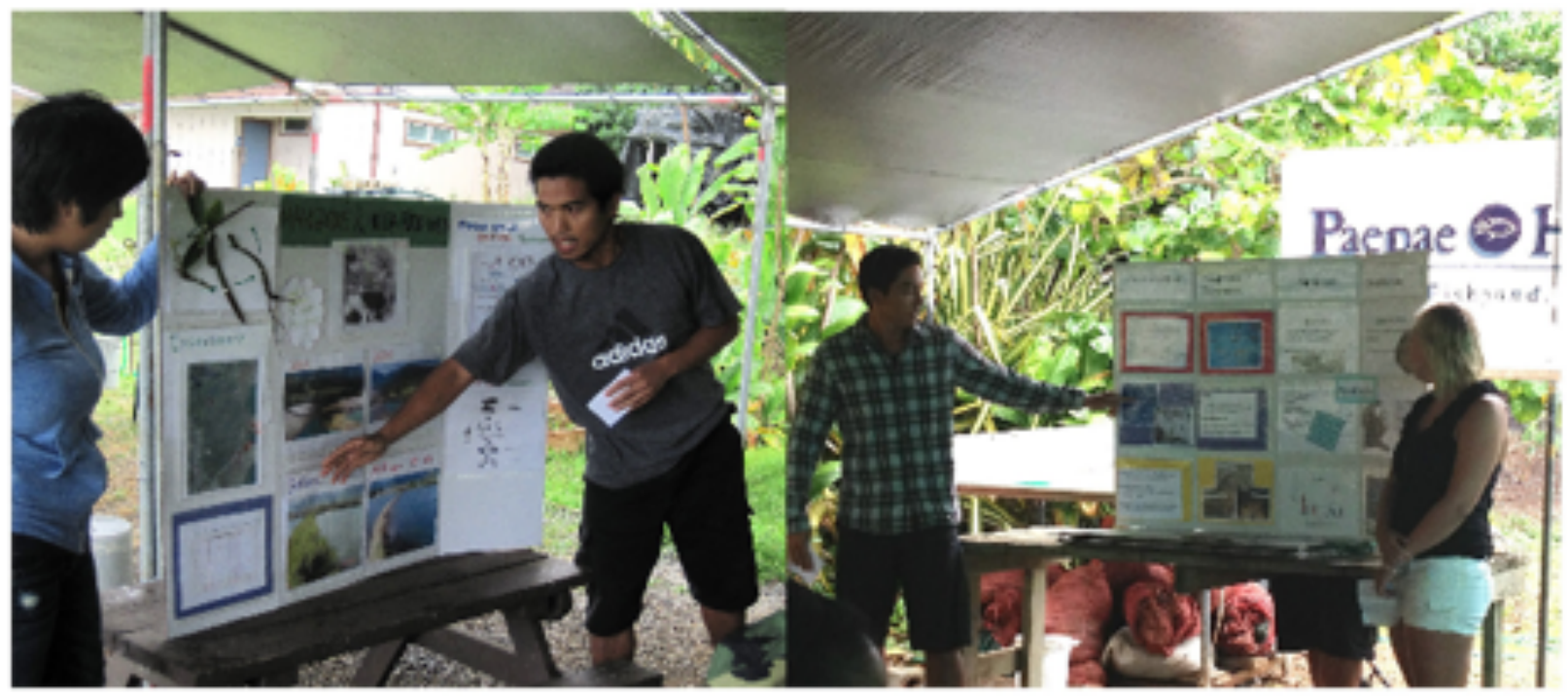

Figure 1. Interns presenting their own research work to community members at the end of the six-month LAIP session. 
cational experience in geoscience research.

3. Bring science and cultural practitioners together through collaborative projects and peer-to-peer learning opportunities.

Written surveys were administered to interns on the first and last days of their internship session. Pre- and post-surveys were anonymous but matched for each participant using birth month and date to track individual responses. In addition, at the end of the 3-year program, all interns were contacted again to complete an anonymous online summary survey about the impact of the program on their education and career interests and choices. The pre-/post-session surveys focused on intern demographics, interest in STEM subjects, perceptions and attitudes about science, motivations, perceptions about the internship, and career plans. The final summative survey contained some questions similar to pre/ post-surveys and new questions related to the influence of LAIP on subsequent educational and training activities, as well as longer-term interests. All assessment activi-ies were approved under the UH Mānoa Internal Review Board for Human Subjects Research as exempt under the Code of Federal Regulations, 45CFR 46.101(b) and included appropriate informed consent (Committee on Human Studies memorandum \#17171).

Both formative and summative surveys were analyzed using descriptive statistics (Schrieber, 2008) to compare differences between pre- and post-session survey results, and to describe short and longer term trends in participant experiences, perceptions, and impacts. Categorical survey questions with explicit ranking options (see survey examples in Supple-mental Materials) were assigned numerical scores to allow a quantitative analysis of pre/post-session comparisons and summative responses. For paired pre- and post-survey items, a two-tailed t-test analysis was employed to determine whether there was a significant difference between student responses. Categorical post-survey and summative survey question data were analyzed using the $95 \%$ t-confidence interval method, with subsequent 2 -sample t-tests as needed for comparisons between confidence intervals with moderate overlap.

\section{RESULTS}

Demographics. A total of 46 interns participated in the LAIP program, with 41 completing both the pre- and post-session surveys. However, all participants completed either a pre- or post-session survey that included demographic information. Participation in the program was both racially and generationally diverse. Forty-one percent of interns designated more than one race on their survey. A slight majority (52\%) self-identified as Caucasian and/or Asian only, while 22 of the 46 interns (48\%) self-identified with at least one minority race or ethnicity considered to be underrepresented

in STEM (Table 1). Of those that identified with a minority race, most $(73 \%)$ chose more than one race to describe themselves, therefore minority identities in Table 1 total more than $48 \%$. Seventeen of the 46 in-terns identified as Hawaiian, Polynesian, or Pacific Islander, representing 37\% of the total number of participants (but 39\% of claimed ethnicities). Hawaiian was overwhelmingly the most prominent minority race identified (claimed by 12 of the 22 minority interns), with Pacific Islander and Native American the second most common (Table 2). Females represented $63 \%$ of intern participants, while males represented $37 \%$.

Although data on participant age was not specifically collected in surveys, interns ranged generationally from high school to college to mid-career/re-career to retiree life stages, with the majority of participants identifying as college students. Interns also varied in the time they or their families have lived in Hawai' $i$, from ancestral to less than one year. Approximately one third reported living in Hawai' $i$ for less than one generation (1-4 years), but most reported that their family has been living in Hawai' $i$ for two or more generations (48\%), and nearly one third of all interns reported having deep ancestral ties to Hawai'i for greater than five generations.

Satisfaction and growth. When asked about their overall satisfaction with the LAIP program in the post-session survey administered on the last day of each internship, interns reported a very high level of satisfaction (Figure 2) and $99 \%$ indicated that they would recommend the program to a friend.

Interns also reported high levels of perceived growth or improvement in their interest, understanding, and competency of several science and environmentally-related metrics specific to the internship program. The question prompt,

Table 1. Self-identification of race or ethnicity by LAIP participants ( $n=46$; most interns claimed more than one ethnicity).

Race or Ethnicity

White and/or Asian only

Any underrepresented minority

Hawaiian/Polynesian/Pacific Islander

Native American

Latino(a)

Black

Middle Eastern

$2.2(1)$ 
Table 2. Self-identification of ethnicity by underrepresented minority LAIP participants $(n=22)$.

\begin{tabular}{lc}
\hline Race or Ethnicity & $\begin{array}{c}\text { \%o of minority claims } \\
\text { (\# of interns) }\end{array}$ \\
\hline Hawaiian & $54.5(12)$ \\
Polynesian & $9.1(2)$ \\
Pacific Islander & $18.2(4)$ \\
Native American & $18.2(4)$ \\
Latino(a) & $9.1(2)$ \\
Black & $4.5(1)$ \\
Middle Eastern & $4.5(1)$ \\
\hline
\end{tabular}

"As a result of the Laulima A 'Ike Pono internship, please rate your growth or improvement in the following areas", offered four categorical response options for each metric item: not improved, slightly improved, moderately improved, or greatly improved. Categorical answers were translated into a numerical score of 1 (not improved) to 4 (greatly improved) for each item and averaged for all interns over all six sessions (Figure 3). Reported growth or improvement was generally high, with an average of 3.0 (moderately improved) or greater for all metrics. The highest perceived gains were seen in interns' improved understanding of the connection between land and ocean, and their ability to identify key organisms in the fishpond (3.56). Hawaiian and Pacific Islander participants reported slightly higher combined gains.

Academic Interests. Overall, interns were much more likely in both pre- and post-surveys to signal an intent to take courses or pursue majors in Biology, Marine Biology, and Geology compared to other STEM disciplines (Physics, Chemistry, Computer Science, Engineering, Math), or Hawaiian Studies. However, this study did not observe substantial changes among participants regarding interest or plans for STEM-related coursework or majors as a result of participation. In fact, while not statistically significant, interns were slightly less likely to express an intention to take a STEM course or pursue a STEM major in almost all STEM disciplines in post-session surveys compared to pre-session surveys. The exception was Marine Biology, in which there was no observable change in student interest between preand post-surveys.

Intern responses also indicated a slight (but insignificant) decline in agreement with the statement, "I'd enjoy being an ocean scientist", although a substantial majority of the pre-session responses to this statement were either "strongly agree" or "agree", suggesting that initial interest in ocean sciences was quite high among interns and remained relatively unchanged by the program.

Career and educational development. To follow up on

\section{Overall Program Satisfaction}

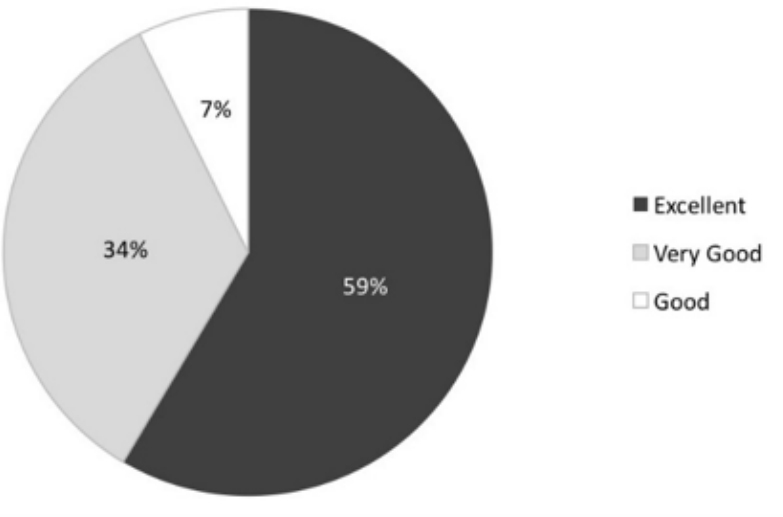

Figure 2. Overall intern satisfaction with the LAIP program as indicated in post-session surveys $(n=41)$.

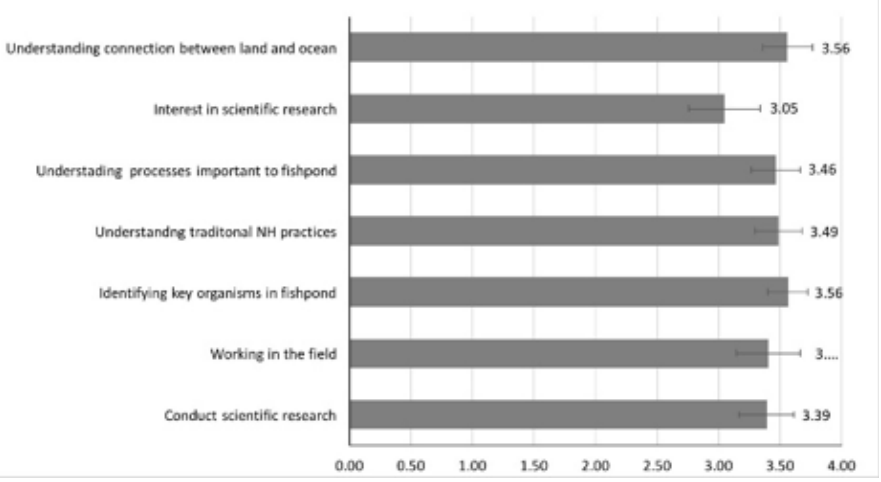

Figure 3. Intern self-reported growth or improvement in various aspects of the LAIP research experience as reported in post-session surveys. Values are averages; bars represent $95 \%$ confidence interval $(n=41)$.

intern academic and career interests, an anonymous online summative survey was administered to all participants at the end of the 3-year program. Approximately half (21) of interns who finished their program responded to the online survey. Although some respondents had perhaps just recently competed the internship, others may had finished the program two or three years earlier. Therefore, the summative survey provided more insight into the potential longer-term impacts of the LAIP program.

In the summative survey, nearly $91 \%$ of responding interns felt that the LAIP program had "influenced their interest in natural science, environmental studies, or resource management" and $71 \%$ indicated their experience had "influenced their interest or participation in environmentally or culturally focused community organizations" (Figure 4). Responding to an open-ended follow-up question, "In what way?", many interns cited actual subsequent participation in environmental, resource management, or conservation related activities or organizations as a result of their LAIP experience (Table 3). A subsequent question addressed the 


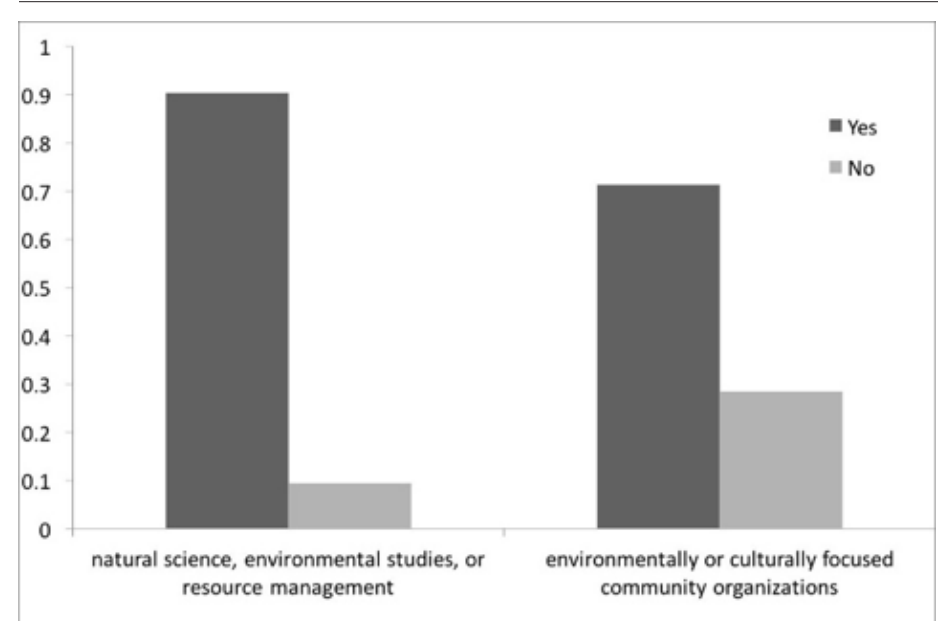

Figure 4. Intern responses in the summative survey to the question, "Has your experience in LAIP influenced your interest in..." $(\mathrm{n}=21)$.

degree to which the LAIP experience had influenced interns' interest in different disciplinary areas. Seventy-one percent indicated their interest had increased "a lot" and 24\% felt their interest had increased "somewhat" in environmental studies and management (Figure 5). While fewer interns responded they experienced "a lot" of in-creased interest in field research as a result of LAIP (57\%), over 95\% of respondents indicated at least some increased interest in field research (Figure 5) after the program. Also, the vast majority of interns felt either "much more confident" $(47.6 \%)$ or "some-what more confident" $(47.6 \%)$ in their ability to engage in scientific research. Only one respondent did not feel more confident in their scientific research abilities as a result of the program (Figure 6).

Forty-three percent of respondents reported that LAIP allowed them to pursue other science or environmental internships, and 38\% had taken additional courses or informal classes to further their under-standing of science, environmental studies, or re-source management as a result of their LAIP experience. Asked about which aspect of the internship had the greatest impact on interns' academic or career pursuits, the actual research experience was most cited (7 of 21 responses) and while most of these were positive impacts, one intern mentioned the "tedious" nature field research as a "reality check" for a pursuing scientific research. The next two most cited aspects were the connection to Hawaiian culture (5 responses), and general encouragement to pursue a degree or take more classes (3 responses).

\section{DISCUSSION}

Participant representation in the LAIP community internship program was generally more ethnically diverse than national averages for undergraduate science research internships (17-20\% underrepresented minorities as reported
Table 3. Intern responses to a question regarding ways in which LAIP had influenced their interest in natural science, environmental studies, or resource management.

It has influenced my interest to come up with solutions to save our ocean here in Hawai' $i$ and to preserve our natural resources.

I found a sense of place at $\mathrm{He}$ 'eia fishpond and sparked an interest in marine management and biology.

The goals of our mentors went over my head a few times, but overall the experience was great. The knowledge that I was able to gain just being there has made me interested in returning to school and finishing my degree in biology.

Working with the LAIP program has showed me that there are many different ways to get involved in a field that I like. It does not have to be purely scientific but also conservation of the land or effects of human activity to the land we live on.

After my experience of LAIP, my concern of resource and environment management has changed. I seriously take action what I can do to save environment with my daily life.

I love how it showed that you never know what will happen on a day to day basis in nature, or what you will encounter. It also helped me to recognize that I had actually learned some useful information to use in the real world. Mostly it made me interested in resource management and the historical and cultural ties it had. We were obtaining data to restore a 800 year old fishpond to be used for a modern community as it had many years before.

It has definitely encouraged my journey to get a Master's Degree. We

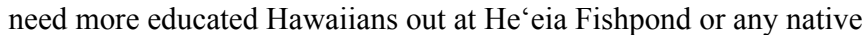
site of cultural significance, conducting research and educating the community.

My experience with LAIP was my first field internship and essentially my introduction into the hands-on experience of resource management. Additionally, it reminded me why I enjoy working in the outdoors so much and why I made the right choice in choosing conservation as the field I want to pursue

LAIP encouraged me to continue to pursue a career that integrates science with cultural practices.

I realized even more that Hawai'i's natural resources need our help, and we are completely capable of assisting in the restoration of our native forests and ecosystems.

It made me realize the sort of path I want to take as I apply to graduate school.

in Lopatto, 2004 and 2007), with substantial participation from Native Hawaiian and Pacific Islander college age students. Similar demographic data on research participation in Hawai' $i$ are currently not available, but the participation of NHPI in LAIP (37\%) was substantially higher than their representation in Hawai'i's overall population (26\%). This greater diversity may be attributed at least in part to a concerted effort to recruit interns with strong connections to the local community; the explicit cultural relevancy of both place and research; and to the integration of contemporary science with indigenous knowledge. These approaches have been supported by other efforts to recruit and retain more racial minority and native students into the sciences (Bang et al., 2009; Johnson and Okoro, 2016). Gender participation 


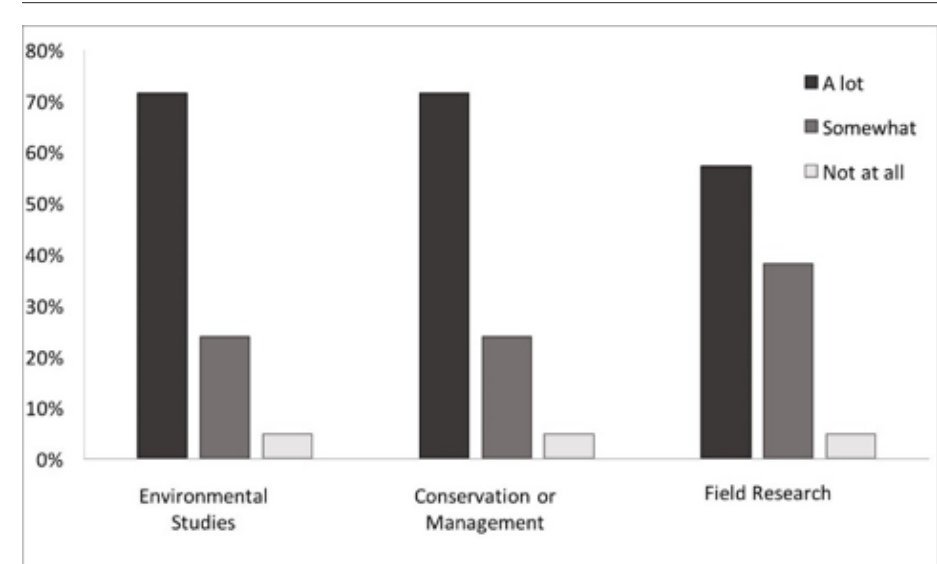

Figure 5. Intern responses in the summative survey to the question, "How much would you say your experience in LAIP increased your interest in..." $(n=21)$..

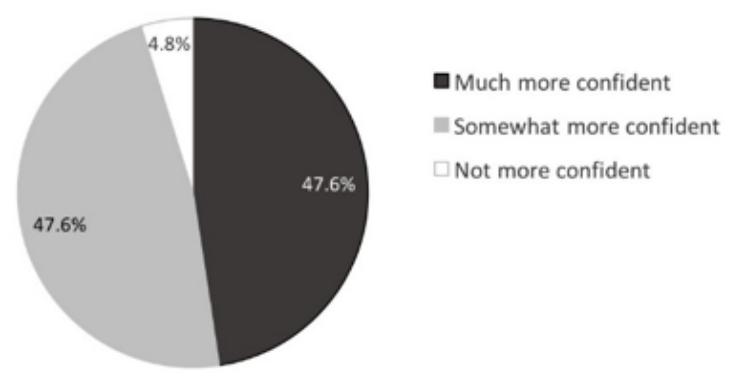

Figure 6. Intern responses in the summary survey to the question, "Do you feel more confident in your ability to engage in scientific research as a result of your LAIP experience?” $(n=21)$.

favored females (63\%) over males, which is comparable but slightly higher than reported national averages of $60 \%$ female and 40\% male (Lopatto, 2004; 2007), as well as recent trends in college enrollment (NCES, 2016).

Participants in LAIP generally reported moderately to greatly increased interests and competencies in science research, understanding, and skills. Other studies investigating the impact of research experiences on student confidence and self-efficacy in both general and specific science skills have shown similar results (see Sadler and McKinney, 2010 for review). Berkes and Hogrebe (2007) and others (Adedokun et al., 2014; Thiry et al., 2012; Jones et al., 2010) suggest that the extent of these gains may be positively correlated with the length of time in a research internship. In the case of LAIP, the internship period of six months falls in the middle range of typical program duration (eight weeks to two years) and would there-fore be expected to generate moderately high results, as was observed. The LAIP research experience did not apparently change participants' immediate plans for further academic study or interest in an ocean science career, which is comparable to results obtained by Lopatto (2004). However, other studies have shown a positive correlation between under-graduate participation in research opportunities and increases in students' expectation of obtaining an advanced degree (Carter et al., 2009; Russell et al., 2007). It has been suggested that while research internships for undergraduates help to entrain highly motivated science students into science career paths, provide important access opportunities for underrepresented minorities, and increase retention of science majors, they may not actually recruit new students into the sciences who weren't already somewhat interested in doing so (Linn et al., 2015; Sadler and McKinney, 2010). The results of this case study tend to align with these latter assertions, at least as they relate to shortterm academic interests in that LAIP participants were no more likely to report plans or interest to take science courses or enroll in science majors at the end of their research experience. However, a substantial proportion of summative survey respondents $(38 \%)$ indicated they had indeed taken additional science-related courses or informal classes as a result of their LAIP experience. This would seem to suggest that although LAIP did not change participants' initial intent to pursue science in a formal academic program, their interest in science-based courses was nevertheless potentially piqued as a result of their participation in LAIP, which they appeared to act upon in seeking subsequent opportunities. This observation may also be related to the large proportion of interns that expressed increased interest and confidence in conducting scientific re-search in both the post-session survey and the later summative survey, indicating an enduring enhancement in their science self-efficacy. Similar re-sults have been observed for undergraduate students participating in research experiences nationally, where participants expressed sustained increased interest and confidence in science several months to over a year following their initial research internship (Lopatto, 2007; Hunter et al., 2007).

The summative survey at the end of the three-year program, potentially six months to three years from when respondents would have completed their internships, provides insight into other potential long-term impacts of the LAIP research experience. Rather than focus on strictly academic pursuits, participants were asked about whether the LAIP internship influenced their engagement in other science-related activities. A surprising majority reported that LAIP had increased their interest in work related to environ-mental studies, conservation, resource management, and fishponds. Indeed, a substantial proportion of interns saw LAIP as providing access to other intern-ships, suggesting that programs like LAIP may play important roles as "gateways" to additional opportunities in participants' science pathways. The summative survey did not collect demographic data on respondents so unfortunately these cannot be correlated to gender, race, or ethnicity. 
Research experiences are a significant factor in enhancing student retention and success, especially underrepresented minorities, in STEM majors (Chang, 2014: Jones et al., 2010; Hathaway, 2002), but studies suggest that non-cognitive factors such social interactions and positive relationships can also strongly impact participants' commitment to remain engaged in science and within the academy (Chang, 2014; Jones et al., 2010; Strayhorn, 2010; Tinto, 1975). Perhaps the same might be true of retention within the broader science community and the scientific institution writ large, which would favor URE approaches such as LAIP that utilize a cohort model and incorporate ample opportunities for students to socialize with each other as well as with mentors, similar to the type of social engagement that might be experienced in a science club or organization (Chang, 2014). Social engagement can lead to a greater sense of belonging to a community, which has also been strongly linked to persistence and interest in STEM majors (Wilson et al., 2015; Freeman et al., 2007; Markus et al., 1993) Another interpretation of these results is that the community service aspect of the experience strengthened participants' sense of empowerment and commitment to civic engagement, which was expressed as increased interest in environmental and conservation action or volunteerism (Knapp et al., 2010). More in-depth studies to elucidate the impacts of STEM research experiences that emphasize social and service learning would help address these questions.

Although a majority of LAIP participants were college students, there are many aspects of this study not directly comparable to the body of literature dedicated to undergraduate research experiences, which limits the ability to more broadly generalize this work. For example, this study did not examine enrollment, GPA, or graduation rates of participants and therefore it was not possible to address the question of academic achievement, retention, or degree attainment as a result the LAIP program. Also, the one-group, pre-test-post-test design lacks randomly assigned test and control groups and therefore must be assumed to have selection bias, and I was not able to directly compare the impacts on the LAIP study group with those participating in other types of internships. The anonymous nature of the summative survey also did not allow longer-term impacts to be correlated with participant demographics.

However, this case study provides a perspective on how place and culture can be integrated into research opportunities and suggests a role for place and cultural relevancy in engaging higher participation of indigenous and underrepresented minority learners such as Native Hawaiian and Pacific Islanders in science research. The study also elucidates several positive impacts of the experience on participants' self-reported interests, plans, and further engagement in science-related endeavors. As discussed, these results align with previous work suggesting that community-based experienc- es focused on place and cultural relevancy are effective in engaging underrepresented minorities in research and have the potential to enhance or elevate participant access to and engagment in other science, environmental, or conservation based activities. Thus, programs that emphasize place and leverage learners' cultural capital (Ovink and Veazy, 2011) may improve overall inclusiveness of science academic and career pathways for a variety of underrepresented learners.

\section{ASSOCIATED CONTENT}

Supplemental information is available.

\section{AUTHOR INFORMATION \\ Corresponding Author}

Judith Lemus, Hawaii Institute of Marine Biology, P.O. Box 1346, Kaneohe, HI 96744; jlemus@hawaii.edu; 808236-7422

\section{Author Contributions}

The manuscript was written through contributions of all authors. All authors have given approval to the final version of the manuscript.

\section{FUNDING SOURCES}

This project was supported by National Science Foundation award GEO09-14516.

\section{ACKNOWLEDGMENTS}

The author is grateful to faculty colleagues (Megan Donahue, Kathleen Ruttenberg, and Florence Thomas) and graduate student research mentors (Rebecca Briggs, Danielle Hull, Sherril Leon Soon, and Megsie Siple) at the University of Hawaii, as well as collaborators Donna Camvel and $\mathrm{Hi}$ 'ilei Kawelo who served as cultural mentors at $\mathrm{He}^{\text {'eia }}$ fishpond.

\section{ABBREVIATIONS}

GPA: grade point average; HIMB: Hawai'i Institute of Ma-rine Biology; LAIP: Laulima A 'Ike Pono; NHPI: Native Hawaiians and Pacific Islanders; NSF: National Science Foundation; STEM: science, technology, engineering, and mathematics; UH: University of Hawai'i;

\section{REFERENCES}

Adedokun, O. A., Parker, L. C., Childress, A., Burgess, W., Adams, R., Agnew, C. R., Leary, J., Knapp, D., Shields, C., Lelievre, S., and Teegarden, D. (2014). 
Effect of time on perceived gains from an undergraduate research program. CBE Life Sciences Education, 13(1). http://doi.org/10.1187/cbe.13-03-0045

Allen-Ramdial, S. A. and Campbell, A. G. (2014). Reimagining the pipeline: Advancing STEM diversity, persistence, and success. BioScience, 64(7), 612-618. http://doi.org/10.1093/biosci/biu076

American Community Survey (2016). U.S. Census Bureau. Retrieved 9/25/17 from: http://census.hawaii.gov/ acs/acs-2016/

Anderson, E. and Kim, D. (2006). Increasing the success of minority students in science and technology. The Unfinished Agenda: Ensuring Success for Stu-dents of Color, 4. American Council on Education.

Bang, M., Medin, D. L., and Atran, S. (2007). Cultural mosaics and mental models of nature. Proceedings of the National Academy of Sciences, 104(35), 1386813874. http://doi.org/10.1073/pnas.0706627104

Bang, M., Medin, D., and Cajete, G. (2009). Improving science education for Native students: Teaching place through community. SACNAS News, 12(1), 8-10.

Bang, M., and Medin, D. (2010). Cultural processes in science education: Supporting the navigation of multiple epistemologies. Science Education, 94(6), 10081026. http://doi.org/10.1002/sce.20392

Berkes, E., and Hogrebe, M. (2007). Undergraduate laboratory research, persistence in science, and the effect of self-efficacy beliefs: A quantitative study. Paper presented at the American Educational Re-search Association, Chicago, IL

Carter, F. D., Mandell, M., and Maton, K. I. (2009). The Influence of on-campus, academic year under-graduate research on STEM Ph.D. outcomes: Evidence from the Meyerhoff Scholarship Program. Educational Evaluation and Policy Analysis, 31(4), 441-462. http://doi.org/10.3102/0162373709348584

Chang, M. J., Sharkness, J., Hurtado, S., and New-man, C. B. (2014). What matters in college for retaining aspiring scientists and engineers from underrepresented racial groups. Journal of Research in Science Teaching, 51(5), 555-580. http://doi.org/10.1002/tea.21146

Cook, S.B., Holloway, A., Lettrich, M. and Yarincik, K. (2016). The ocean science graduate education landscape: A 2015 perspective. Oceanography, 29(1), 16-21. https://doi.org/ 10.5670/oceanog.2016.04.

Freeman, T. M., Anderman, L. H., and Jensen, J. M. (2007). Sense of belonging in college freshmen at the classroom and campus levels. Journal of Experimental Education, 73(S3), 203-220. http://doi.org/10.3200/ JEXE.75.3.203-220

Gibson, B. A., and Puniwai, N. (2006). Developing an archetype for integrating native Hawaiian traditional knowledge with earth system science education.
Journal of Geoscience Education, 54(3), 287-294.

Gilligan, M., and Ebanks, S. (2016). The Ocean Science Social Diversity Challenge. Oceanography, 29(1), 55-57. http://doi.org/10.5670/oceanog.2016.04

Gilligan, M.G., Verity, P.G., Cook, C.B., Cook, S.B., Booth, M.G. and Frischer, M.E. (2007). Building a diverse and innovative ocean workforce through collaboration and partnerships that integrate research and education: HBCUs and marine lab- oratories. Journal of Geoscience Education, 55(6), 531-540.

Hathaway, R.S, Nagda, B. A. and Gregerman, S. R. (2002). The relationship of undergraduate research participation to graduate and professional education pursuit: and empirical study. Journal of College Student Development, 43(5), 614-31.

Hunter, A., Laursen, S. L., and Seymour, E. (2007). Becoming a scientist: The role of undergraduate re-search in students' cognitive, personal, and professional development. Science Education, 91(1), 36-74. https://doi. org/10.1002/sce. 20173

Johnson, A., and Okoro, M. H. (2016). How to recruit and retain underrepresented minorities. American Scientist, 104(2), 76. https://www.americanscientist.org/ article/how-to-recruit-and-retain-underrepresented-minorities

Jones, M. T., Barlow, A. E. L., and Villarejo, M. (2010). Importance of Undergraduate Research for Minority Persistence and Achievement in Biology. The Journal of Higher Education, 81(1), 82-115. http://doi. org/10.1353/jhe. 0.0082

Kana'iaupuni, S. M. (2006). This land is my land: the role of place in Native Hawaiian identity. Hūlili: multidisciplinary research on Hawaiian well-being, 3(1), 281-307.

Kimmerer, R.W. (2002). Weaving Traditional ecological knowledge into biological education: A call to action. BioScience, 52(5), 432-438.

Knapp, T., Fisher, B., and Levesque-Bristol, C. (2010). Service-learning's impact on college students' commitment to future civic engagement, self-efficacy, and social empowerment. Journal of Community Practice, 18(2-3), 233-251. http://doi.org/10.1080/1070 5422.2010 .490152

Kuwahara, J.L.H. (2013). Impacts of a place-based science curriculum on student place attachment in Hawaiian and Western cultural institutions at an urban high school in Hawai'i. International Journal of Science and Mathematics Education, 11, 191-212.

Linn, M. C., Palmer, E., Baranger, A., Gerard, E., and Stone, E. (2015). Undergraduate research experiences: Impacts and opportunities. Science, 347(6222). http:// 
doi.org/10.1126/science. 1261757

Lopatto, D. (2004). Survey of undergraduate research experiences (SURE): first findings. Cell Biology Education, 3(4), 270-277. https://doi.org/10.1187/cbe.07060039

Lopatto, D. (2007). Undergraduate research experiences support science career decisions and active learning. CBE Life Sciences Education, 6, 297-306. http://doi. org/10.1187/cbe.07

Markus, G., Howard, J., and King, D. (1993). Integrating community service and class-room instruction enhances learning: Results from an experiment. Educational Evaluation and Policy Analysis, 15(4), 410 419

National Academies of Sciences; Engineering; and Medicine (2016). Barriers and Opportunities for 2-Year and 4-Year STEM Degrees Systemic Change to Support Diverse Student Pathways. Committee on Barriers and Opportunities in Completing 2-Year and 4-Year STEM Degrees; Board on Science Education and Board on Higher Education and the Workforce. Washington; DC: The National Academies Press.

National Center for Education Statistics. (2016). Digest of Education Statistics: 2015. Retrieved from https:// nces.ed.gov/programs/digest/d15/index.asp

National Research Council (2011). Expanding Underrepresented Minority Participation: America's Science and Technology Talent at the Crossroads. Committee on Underrepresented Groups and Expansion of the Science and Engineering Workforce. Committee on Science, Engineering, and Public Policy, Policy and Global Affairs. Washington, DC: The National Academies Press.

Ovink, S. M., and Veazey, B. D. (2011). More Than "Getting Us Through:" A case study in cultural capital enrichment of underrepresented minority undergraduates. Research in Higher Education, 52(4), 370-394. http://doi.org/10.1007/s11162-010-9198-8

Riggs, E. (2005). Field-based education and indigenous knowledge: Essential components of geoscience education for native American communities. Science Education, 89(2), 296-313.

Riggs, E. M., Robbins, E., and Darner, R. (2007). Sharing the Land: Attracting Native American Students to the Geosciences. Journal of Geoscience Education, 55(6), 478-485. http://doi.org/10.5408/1089-999555.6 .478

Russell, S. H., Hancock, M. P., Mccullough, J., Russell, S. H., Hancock, M. P., and Mccullough, J. (2007). Benefits of Undergraduate Research Experiences. Science, 316(5824), 548-549.
Sadler, T. D., and Mckinney, L. (2010). Scientific re-search for undergraduate students: A review of the literature. Journal of College Science Teaching, 39(June), $43-49$.

Schreiber, J.B. (2008). Descriptive Statistics. In: The SAGE Encyclopedia of Qualitative Research Methods. L.M. Given (ed). SAGE Publications, Inc. Thousand Oaks, CA. DOI: http://dx.doi.org/10.4135/9781412963909. n108

Semken, S. (2005). Sense of place and place-based introductory geoscience teaching for American Indian and Alaska Native undergraduates. Journal of Geoscience Education, 53(2), 149-157.

Siple, M. C., and Donahue, M. J. (2013). Invasive mangrove removal and recovery: Food web effects across a chronosequence. Journal of Experimental Marine Biology and Ecology, 448, 128-135. http://doi. org/10.1016/j.jembe.2013.06.008

Snively, G., and Corsiglia, J. (2000). Discovering indigenous science: Implications for science education. Science Education, 85, 6-34. http://doi.org/10.1002/1098237X(200101)85:1<6::AID-SCE3>3.0.CO;2-R

Strayhorn, T.L. (2010). When race and gender collide: Social and cultural capital's influence on the academic achievement of African American and Latino males. The Review of Higher Education, 33(3), 307-332. http://doi.org/10.1353/rhe.0.0147

Sutherland, D., and Swayze, N. (2012). The importance of place in indigenous science education. Cultural Studies of Science Education, 7(1), 83-92. http://doi. org/10.1007/s11422-011-9371-1

Thiry, H., Weston, T. J., Laursen, S. L., and Hunter, A. B. (2012). The benefits of multi-year research ex-periences: Differences in novice and experienced students' reported gains from undergraduate re-search. CBE Life Science Education, 11, 260-272. http:// www.lifescied.org/content/11/3/260 doi: 10.1187/ cbe.11-11-0098; pmid: 22949423

Tinto, V. (1975). Dropout from higher education: A theoretical synthesis of recent research. Review of Educational Research, 45(1), 89-125.

University of Hawa'i Institutional Research and Analysis Office. https://www.hawaii.edu/iro/. Accessed 26 September 2017.

Wilson, D., Jones, D., Bocell, F., Crawford, J., Kim, M. J., Veilleux, N., Floyd-Smith, T., Bates, R., and Plett, M. (2015). Belonging and academic engagement among undergraduate STEM students: A multi-institutional study. Research in Higher Education, 56(7), 750 776. http://doi.org/10.1007/s11162-015-9367-x 